CUNEO, Silvio: "Recensión: Corn, Emanuele, Il Femminicidio come Fattispecie Penale.

Soria, comparazione, prospettive, Nápoles: Editoriale Scientifica, 2017, 256 páginas"

Polít. Crim. Vol. 15, № 29 (Julio 2020), Rec. 1, pp. 483-487

[http://politcrim.com/wp-content/uploads/2020/07/Vol15N29R1.pdf]

\title{
Recensión: CORN, Emanuele (2017): Il Femminicidio come Fattispecie Penale. Soria, comparazione, prospettive (Nápoles: Editoriale Scientifica).
}

\section{Review: CORN, Emanuele (2017): Il Femminicidio come Fattispecie Penale. Soria, comparazione, prospettive (Nápoles: Editoriale Scientifica).}

\author{
Dr. Silvio Cuneo Nash \\ Profesor investigador, Facultad de Derecho y Humanidades de la Universidad Central de \\ Chile \\ silvio.cuneo@ucentral.cl
}

Emanuele Corn comienza su libro Il Femminicidio come Fattispecie Penale aclarando que se trata de un trabajo de Derecho penal. Sin embargo, debo, desde el inicio, manifestar una discrepancia con el autor, toda vez que los temas tratados en esta obra trascienden lo estrictamente jurídico, nutriendo al lector con datos empíricos, debates filosóficos, estudios de género y análisis sociológicos. Así, el autor, al complementar el estudio jurídico con otras disciplinas, enriquece el análisis de un fenómeno que requiere de un examen interdisciplinario.

Es evidente que Emanuele Corn no es un negacionista del fenómeno del feminicidio. Sin embargo, parte en el capítulo primero invitándonos a mirar las cifras, y lo primero que llama la atención es que los números son menos alarmantes de lo que pudiera pensarse. Por otro lado, la aproximación al fenómeno del feminicidio, con bases empíricas y citando diversos trabajos de campo, muestran que es en el contexto intrafamiliar donde se perpetra gran parte de la violencia asesina contra las mujeres.

En el capítulo segundo se estudian las etapas del discurso feminista que llega a posicionar el feminicidio como un tema urgente y capital. Llama la atención la emergencia tardía —en relación a otros temas centrales del feminismo - del feminicidio en la agenda feminista. La cuestión genera muchas interrogantes que son tratadas con una mirada principalmente sociológica. La cobertura mediática, sumado a una masificación del movimiento feminista en diversas partes del mundo, puede ayudarnos a comprender el porqué de manera tan tardía, pero también en un breve lapso, la violencia asesina en contra de las mujeres se instaló en las agendas públicas como un tema central. Posiblemente, explica el autor, la violencia en el contexto intrafamiliar no se advertía como un problema de todas las mujeres, sino sólo de algunas (aquellas que habían elegido a un mal compañero), y esto podría explicar por qué el tema tardó tanto en imponerse.

En el capítulo tercero se estudian las normas internacionales sobre violencia contra las mujeres. El estudio del derecho internacional de los Derechos Humanos resulta fundamental en esta materia, puesto que aquí es donde encontramos uno de los principales instrumentos que los movimientos por la reivindicación de una vida libre de violencia contra las mujeres han utilizado a nivel global para conseguir sus propósitos. Luego, en el cuarto capítulo, se 


\section{Polít. Crim. Vol. 15, № 29 (Julio 2020), Rec. 1, pp. 483-487 [http://politcrim.com/wp-content/uploads/2020/07/Vol15N29R1.pdf]}

estudian diversas legislaciones nacionales (especialmente latinoamericanas) que contemplan un tipo penal especial de feminicidio, y las diversas maneras en que se tipifica dicho delito. De la observación acuciosa de las distintas legislaciones, el autor se cuestiona si está bien o mal la existencia de un tipo penal de feminicidio. Su primera respuesta - de penalista liberal- es que en principio no es necesario y que ya basta de nuevos tipos penales. Sin embargo, en el capítulo siguiente parece llegar a una conclusión contraria. En efecto, el quinto y último capítulo, en el que se analiza la situación italiana, el autor realiza propuestas en pro de incorporar al catálogo de tipos penales de su país el delito de feminicidio.

El libro, lejos de cerrar un debate que recién comienza, deja varias interrogantes que pueden ser motor de nuevos estudios y reflexiones en torno a cuestiones fundamentales. Las respuestas a la violencia asesina en contra de las mujeres deben ser analizadas desde la abstracción de las teorías de la pena hasta los análisis de la realidad del fenómeno. En el fondo, de lo que se trata, es de saber si efectivamente el Derecho Penal — que siempre opera ex post - es el llamado a proteger a las mujeres que históricamente han padecido la violencia machista; o si sólo se trata de una tipología penal de valor simbólico que fundamente, ya sea un tipo penal particular, ya sea una mayor punitividad. Al respecto, el profesor Corn, señala que la utilidad de una tipificación del feminicidio serviría, no tanto para fundamentar una mayor punitividad, sino para visualizar algo que estuvo mucho tiempo invisibilizado.

Entre las muchas cosas destacables del libro quisiera subrayar su análisis de la situación chilena. No se trata sólo de un examen que da cuenta del conocimiento del profesor italiano de nuestra realidad sino que, aún más valioso que la mera indagación de la situación y la legislación chilena, el libro nos ayuda a comprenderlo dentro de un contexto más global, explicando cómo Chile sigue una tendencia que no resulta extraña a la propensión latinoamericana.

También digno de destacar es la mención del suicidio-feminicidio, en el que las mujeres terminan quitándose la vida a causa de la violencia física, psicológica y/o económica que tienen que, y no pueden, soportar. Esta situación, aunque evidente, resulta invisibilizada por las muertes más sanguinarias que atrapan casi la totalidad de atención mediática. Y en relación a la morbosidad mediática que puede distorsionar la magnitud del fenómeno, también resulta sumamente importante el llamado a la prudencia que realiza el propio autor quien, criticando el populismo que suele alimentar a las legislaciones penales, advierte que la entidad de la sanción penal no puede calibrarse en base a la frecuencia estadística de los eventos, toda vez que el bien jurídico vida de las personas tiene un mismo valor para el Derecho penal en cualquier momento de la existencia. Luego, para graficar lo que sostiene, de manera irónica, plantea lo absurdo que resultaría agravar los hurtos de supermercados en los horarios de cierre fundándose en que en dichos momentos es cuando más hurtos se perpetran.

Corn, conociendo el efecto comunicativo de la norma penal, critica a los legisladores chilenos, quienes, con la creación del tipo penal de femicidio, enviaron a la opinión pública una señal de que algo se estaba haciendo, cuando en realidad lo que se hizo fue modificar lo menos posible el status quo. Esta situación, que ya antes Corn había calificado de "revolución 


\section{Polít. Crim. Vol. 15, No 29 (Julio 2020), Rec. 1, pp. 483-487 [http://politcrim.com/wp-content/uploads/2020/07/Vol15N29R1.pdf]}

tímida", ahora la acusa de ser una actitud gattopardesca, que asegura que todo cambie para que todo siga igual. En efecto, sostiene Corn, desde un punto de vista técnico, el femicidio en Chile, a pesar de ser un tipo penal autónomo respecto del delito de parricidio, se encuentra completamente absorbido por éste, por cuanto engloba todos sus elementos típicos.

Entre las últimas reflexiones del texto, el autor aclara que el especial énfasis que requiere el problema de la violencia asesina contra las mujeres no viene dado porque matar a una mujer sea algo distinto o más grave per se que matar a un hombre, sino en el hecho de que hoy, en esta fase histórica de nuestra sociedad, detrás de muchas muertes de mujeres existen elementos de discriminación en los que se encontraría un disvalor especial.

De manera personal, y quizá alejándome un poco del planteamiento del profesor de Trento, creo que conviene tener presente que el feminismo puede entenderse y fundamentarse de maneras muy diversas. Sin embargo, lo que debe estar detrás de todo feminismo es un anhelo de igualdad de derechos, de los derechos de la mujer en particular y, en general, una lucha hacia una igualdad más amplia. Esta idea parece difícil de conciliar con un feminismo punitivista. Y esto porque el Derecho Penal es selectivo y, como instrumento de control social, fomenta las desigualdades y golpea y controla principalmente a las clases sociales más bajas. Por lo mismo, el punitivismo es incompatible con un anhelo de igualdad. Posiblemente esta cuestión, aunque obvia, no resulte tan clara para gran parte del movimiento feminista que aboga por una mayor punitividad.

Por otro lado, partiendo de la base de un repudio generalizado por los feminicidios, lo fundamental es conocer e implementar políticas públicas (especialmente educativas) que puedan disminuir estos, ante lo cual resulta muy difícil sostener, con cifras concretas en la mano, que le quepa al Derecho Penal algún efecto preventivo. De ahí que la existencia de un tipo penal de feminicidio sólo puede fundarse en criterios de reprobación y justicia, no así en posibles fines preventivos.

Por otro lado, resulta irreconciliable para los propugnadores de un Derecho Penal de ultima ratio defender un pretendido Derecho Penal simbólico, dado que toda concepción simbólica del Derecho penal supone concebir la pena como medio para fines extrínsecos a su propia entidad, lo que siempre conllevará, se quiera o no, la utilización del individuo para fines ajenos a sí mismo, con el consiguiente desconocimiento o menosprecio de su dignidad.

La lectura del libro del profesor Emanuele Corn nos llena de múltiples interrogantes y nos invita a reflexionar y trabajar en un problema urgente que debe ser tratado de manera prioritaria por la comunidad jurídica.

El texto, obligatorio para quien quiera introducirse en los estudios sobre el delito de feminicidio, colma un vacío en un tema del que tanto se habla, pero poco se sabe. Recomiendo sin ninguna duda su lectura para los estudiosos del Derecho Penal, y también para todo aquel que quiera encontrar distintos elementos para una mejor comprensión de un fenómeno apremiante. Espero, asimismo - y estoy seguro que así también lo espera

${ }^{1}$ CORN (2014), pp. 103-136. 
Polít. Crim. Vol. 15, No 29 (Julio 2020), Rec. 1, pp. 483-487

[http://politcrim.com/wp-content/uploads/2020/07/Vol15N29R1.pdf]

Emanuele Corn-— que de la lectura del libro surjan nuevas interpretaciones, críticas y discrepancias a lo por él planteado. Auguro la mayor difusión posible y una pronta traducción al castellano. 


\section{Bibliografía}

CORN, Emanuele (2017): Il Femminicidio come Fattispecie Penale. Soria, comparazione, prospettive (Nápoles: Editoriale Scientifica).

CORN, Emanuele (2014): "La revolución tímida. El tipo de femicidio introducido en Chile por la ley $\mathrm{N}^{\circ} 20.480$ desde una perspectiva comparada", en: Revista de Derecho Universidad Católica del Norte (vol. 21 N²), pp. 103-136. 